\title{
Comparative value of a simulation by gaming and a traditional teaching method to improve clinical reasoning skills necessary to detect patient deterioration: a randomized study in nursing students
}

\author{
Antonia Blanié ${ }^{1,2,3,4^{*}}$ (D) Michel-Ange Amorim ${ }^{3,4}$ and Dan Benhamou ${ }^{1,2,3,4}$
}

\begin{abstract}
Background: Early detection and response to patient deterioration influence patient prognosis. Nursing education is therefore essential. The objective of this randomized controlled trial was to compare the respective educational value of simulation by gaming (SG) and a traditional teaching (TT) method to improve clinical reasoning (CR) skills necessary to detect patient deterioration.

Methods: In a prospective multicenter study, and after consent, 2nd year nursing students were randomized into two groups:

- Simulation by gaming "SG": the student played individually with a serious game consisting of 2 cases followed by a common debriefing with an instructor;

- Traditional Teaching "TT": the student worked on the same cases in text paper format followed by a traditional teaching course with a PowerPoint presentation by an instructor.
\end{abstract}

CR skill was measured by script concordance tests (80 SCTs, score 0-100) immediately after the session (primary outcome) and on month later. Other outcomes included students' satisfaction, motivation and professional impact.

Results: One hundred forty-six students were randomized. Immediately after training, the SCTs scores were $59 \pm 9$ in SG group $(n=73)$ and $58 \pm 8$ in TT group $(n=73)(p=0.43)$. One month later, the SCTs scores were $59 \pm 10$ in SG group $(n=65)$ and $58 \pm 8$ in $\Pi$ group $(n=54)(p=0.77)$. Global satisfaction and motivation were highly valued in both groups although significantly greater in the SG group $(p<0.05)$. The students declared that the training course would have a positive professional impact, with no difference between groups.

Conclusions: In this study assessing nursing student CR to detect patient deterioration, no significant educational difference (SCT), neither immediate nor 1 month later, was observed between training by SG and the TT course. However, satisfaction and motivation were found to be greater with the use of SG.

Trial registration: ClinicalTrials.gov; NCT03428269. Registered 30 january 2018.

Keywords: Serious games, Simulation, Clinical reasoning, Motivation, Nursing students, Deterioration, Script concordance test

\footnotetext{
* Correspondence: antonia.blanie@aphp.fr

${ }^{1}$ Centre de simulation LabForSIMS, Faculté de médecine Paris Saclay, 94275

Le Kremlin Bicêtre, France

²Département d'Anesthésie-Réanimation, CHU Bicêtre, 78, rue du Général

Leclerc, 94275 Le Kremlin Bicêtre, France

Full list of author information is available at the end of the article
}

(c) The Author(s). 2020 Open Access This article is distributed under the terms of the Creative Commons Attribution 4.0 International License (http://creativecommons.org/licenses/by/4.0/) which permits unrestricted use, distribution, and reproduction in any medium, provided you give appropriate credit to the original author(s) and the source, provide a link to the Creative Commons license, and indicate if changes were made. The Creative Commons Public Domain Dedication waiver (http://creativecommons.org/publicdomain/zero/1.0/) applies to the data made available in this article, unless otherwise stated. 


\section{Background}

Patient deterioration detection is a major healthcare problem. Indeed, acute patient clinical deterioration is often preceded by a modification of physiological parameters 6 to $24 \mathrm{~h}$ before the event $[1,2]$. The association of i) early detection ii) rapidity of response and iii) quality of clinical response, influence the patient's prognosis. Many studies have shown that delayed diagnosis of an ongoing complication increases morbidity and mortality $[2,3]$. The education of nurses, who are frontline healthcare providers, is therefore essential. In French nursing institutes, theoretical training to detect patient deterioration is currently performed by traditional teaching courses and/or paper case-based courses. Simulationbased education is recommended for the training of healthcare professionals [4-6]. When compared with high-fidelity simulation, serious games also possess an interesting immersive capacity and may be used to train a large number of healthcare professionals in a limited amount of time with reduced educational resources.

Serious games are video games developed specifically with an educational purpose [7, 8]. They can be computer-based or use more immersive technologies such as virtual reality combined with head-mounted display. Serious games can promote experiential learning, as described by Kolb [9], when they include a 3D realistic environment close to real life. They can be used to train both technical and non-technical skills [10-14]. We developed a serious game, named LabForGames Warning, which aims to improve nursing students' interprofessional communication behavior and their capabilities to detect patient clinical deterioration. Several studies using serious games in healthcare have already been published and have been included in meta-analyses [10-14], but careful analysis shows that serious games are difficult to compare due to the differences in the populations studied, the variety of game designs, topics included, pedagogical objectives and modalities of assessment. Comparative analysis between the educational value of a serious game and a traditional course is already available for cardiac arrest management, trauma triage and other domains, but it is uncertain whether results obtained in one field apply to the others [13-18] . In addition, several studies have used a serious game to train nurses in the detection of patient deterioration, but are characterized by a high level of heterogeneity and sometimes provide neutral results [19-22]. One randomized study, aiming to compare the assessment and the management of clinical deterioration, in which either a virtual patient or a mannequin was used, found that both simulation methods (serious game and highfidelity) could be effective in improving nursing-student score performance, with no difference between the two methods [23]. More specifically, few studies have assessed how components of clinical reasoning skills necessary to detect patient deterioration are modified by the use of serious games. Most serious games studies use one result of clinical reasoning (treatment, diagnosis or triage) but an objective criterion evaluating all clinical reasoning skills has rarely been used so far [15, 20]. As described by Levett-Jones et al. [24], clinical reasoning is "the process by which nurses collect cues, process the information, come to an understanding of a patient problem or situation, plan and implement interventions, evaluate outcomes, and reflect on and learn from the process". Furthermore, the positive impact of instructorstandardized debriefing is clearly demonstrated in high fidelity simulation [25] but its place is unclear regarding the use of a serious game [23, 26].

The objective of this study was to compare the respective value of simulation using the above-mentioned serious game with debriefing and a traditional teaching method to improve the clinical reasoning skills necessary to detect patient deterioration in nursing students.

\section{Methods}

\section{Serious game development}

The serious game project was promoted by the simulation center of Paris-Sud University (LabForSIMS) in collaboration with four nursing institutes (Sud Francilien, Perray Vaucluse, Paul Guiraud and Etampes) through a grant from the Ile-de-France Regional Health Agency (ARS). Four virtual clinical cases were created through an iterative dialogue between the pedagogical team and the the software designer (Interaction Healthcare ${ }^{\ominus}$, Levallois-Perret, France). The pedagogical team were clinical experts (instructors of four nursing schools and anesthesiologists) who were also involved in the simulation center. The predefined educational objectives of the serious game were detection of clinical deterioration and communication. In the game, a nurse was expected to identify clinical deterioration in different clinical situations and warn the medical team appropriately, in consideration of the patient's clinical severity. As the serious game focuses on nursing students, the objectives had to comply with the French official nursing repository [27]. The game is not played in real time but a clock was presented on the screen which indicated the time flow. In each clinical scenario, three consecutive steps (mildly abnormal, moderate aggravation and severe condition) were constructed to reproduce a specific complication of increasing severity, with the aim of introducing the concept of early warning signs [28]. In the present study, only two of the four available cases were used (Additional file 1):

- Postoperative hemorrhage case: an adult female patient who had undergone a scheduled total hip 
replacement earlier in the day and who is lying in her ward room bed immediately after arrival from the post-anesthesia care unit. Postoperative hemorrhage is progressively occurring from the surgical site.

- Brain trauma case: an elderly patient with dementia living in a nursing home, whose anticoagulation is associated with progressively developing neurological deterioration after brain trauma from a fall.

Learning safe and standardized communication was an additional educational objective [29, 30]. We chose to train nursing students to the SBAR method, ("Situation, Background, Assessment, Recommendation »), adapted into French by the French Health Authority [27].

Before starting to play, a tutorial allowed a first approach to the software. In the game, the player was a nurse. The nurse played on a computer and could move in the 3-D environment (Additional file 1). The student's actions were obtained by clicking on different interactive areas. For example, regarding clinical examination, the student could check arterial pressure, motor response, etc. Patient questioning was performed by a scroll-down menu of pre-determined options but the player could hear the patient's answer. The student had also access to the patient's file (prescription, nurse handover transcripts ...) and could call the physician with a virtual phone and present the case using the SBAR method.

At the end of each scenario, an automatic feedback was presented to the student, which included main guidelines and key messages as well as a global and detailed score according to a grid which had been constructed by the pedagogical team during the development phase of the SG. The student's actions regarding clinical examination (e.g., checking of arterial pressure, pain assessment...) and the student' decision (e.g., call for the physician...) were scored using positive, negative or neutral points depending on the different steps of the case. Moreover, positive or negative points were attributed to the quality of the communication during the SBAR tool part of the game. This score and the playtime were not used to evaluate the students in this present study.

\section{Study description}

After informed and written consent, 2nd year nursing students were included and randomized into two groups: the simulation by gaming group (SG group) and the traditional teaching group (TT group) (Fig. 1).

Training sessions for the detection of clinical deterioration were planned in the four nursing institutes. The group sessions lasted $2 \mathrm{~h}$ and each involved 15 students. The teachers were nurse instructors involved in the program and trained in simulation. The students had not been informed of the study objectives, nor to which group they were to be assigned (single-blind). Randomization was carried out on the morning preceding the session with the use of the random Excel function (by A.B.). The sessions and assessment for the two groups were run simultaneously in different rooms.

In the SG group, the students played individually on computers and were given the two previously described cases of LabForGames Warning (Additional file 1). A whole-group debriefing was performed after the cases by trained instructors. Debriefing (different from serious game's automatic feedback) was performed according to the methodology used in a simulation session (reaction, analysis and synthesis phases) $[25,31,32]$ in which reflexive practice is promoted by a positive interaction between students and instructor.

In the traditional teaching group, the students individually analyzed the same 2 cases which were presented in text paper format (Additional file 2) (without instructor). Then, they attended a PowerPoint slide kit traditional teaching course on the topic with an instructor (Additional file 3).

\section{Assessment method}

All players answered a questionnaire at the end of the session which included questions on sex, age, postgraduate experience and previous video gaming activity (entertainment and professional education). The primary outcome measure was the student's clinical reasoning skills regarding detection of clinical deterioration as measured by script concordance tests (SCTs) immediately after the session. SCTs have been validated as an effective tool of assessing clinical reasoning skills (Kirkpatrick level 2) and are considered to be an objective and quantitative assessment method. SCTs have already been used in nursing students [33-37]. Based on the script theory [37], SCTs are used to compare if students' decisions, made from their knowledge networks (scripts), are in line with the decisions taken by a panel of experts. The SCTs used in this study were carefully prepared by following the guideline described by Charlin et al. and Fournier et al. to obtain a high level of fidelity and validity [33-35]. An example of SCT is presented in Table 1. SCTs are case-based tests consisting of short scenarios, and for each the trainee has to interpret newly formulated information against the baseline one to modulate the final decision with the use of a five-point Likertscale. This final decision could be a diagnosis but also a treatment, an action (prescribe or perform a complementary exam, call for help ...). Because the numerous short cases used explore the different types of decision, the SCTs test the different skills of clinical deterioration reasoning and not just the diagnosis. 


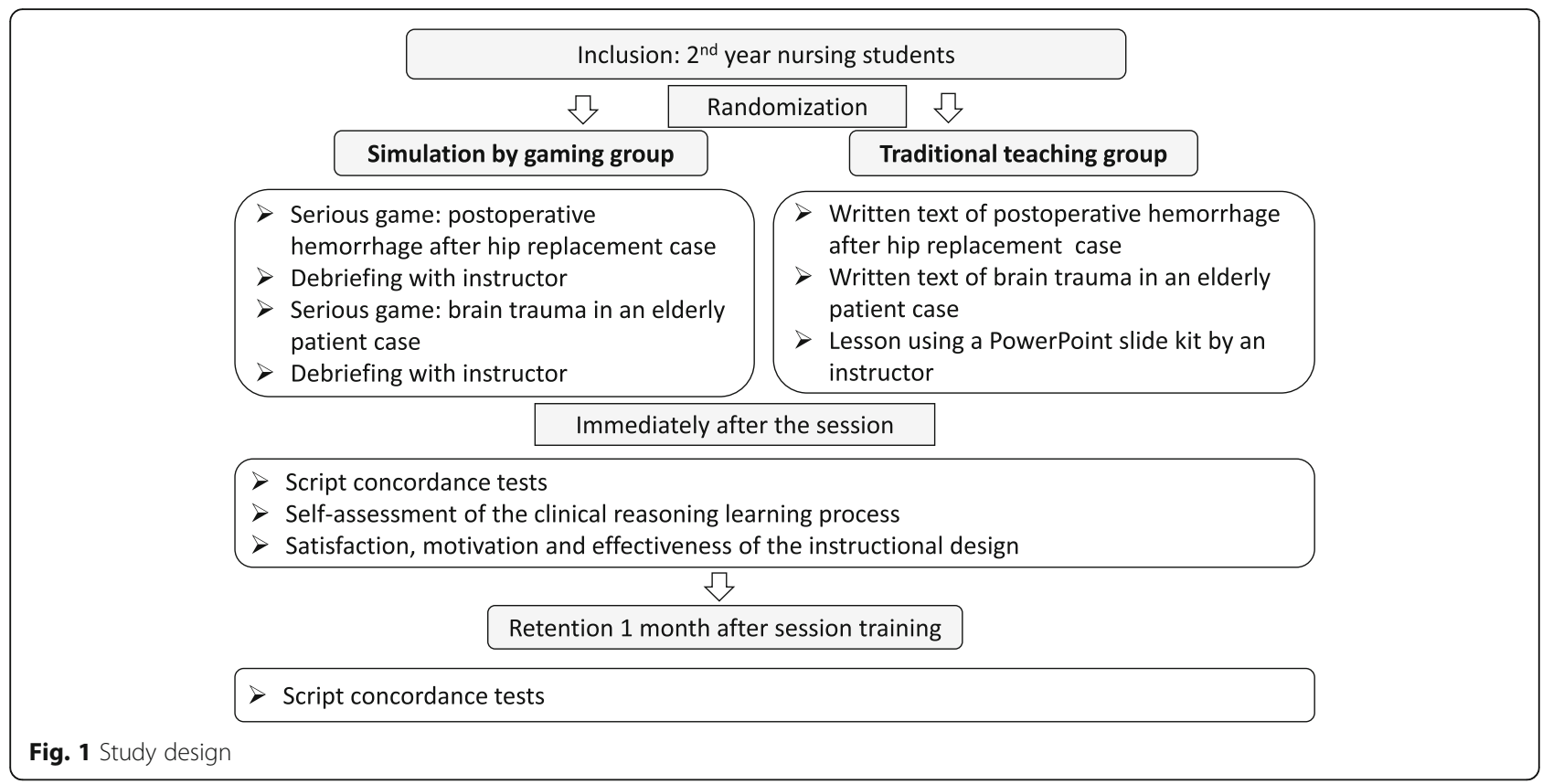

The standard SCT scoring method uses the aggregate method in which scoring is in relation to the scores obtained by a panel of reference experts in the respective domain. After scoring the single items, a raw summary score is obtained by summing up all of cases. In order to make the scores interpretable and comparable, the raw summary score is normalized where the expert mean performance is set at 80 points, and the standard deviation at 5 points. This normalization is a $\mathrm{Z}$ transformation as suggested by Charlin et al. [38]. The analysis of SCTs includes variance calculation and scores obtained by an aggregation method using the following file (https://www.cpass.umontreal.ca/recherche/groupe-derecherche-cpass/axes-de-recherches/concordance/tcs/ corriger_tcs/). Ninety-three SCTs in connection with the pedagogical objectives were constructed by 3 expert instructors (2 anesthesiologists and 1 nurse instructor). Eleven other experts were subsequently included in the reference panel ( 6 anesthesiologists and 5 nurse instructors). After analysis of the expert panel responses, 13
SCTs were removed because of high variance (variance $>1$ ) and 80 SCTs were finally used. After optimization of the tool, Cronbach's alpha was 0.75 (95 CI: 0.70$0.81)$. The mean SCT score obtained by experts $(n=11)$ was $83.3 \pm 3.6$ (95 CI: 82.2-84.4). The students were trained to use the SCT format just before the training session. The same 80 SCTs were applied immediately and 1 month after the session, to capture retention of knowledge, with the use of an online module.

In addition, secondary outcome measures were assessed. A self-assessment of the perceived change of the clinical reasoning process was recorded after the session to assess the various steps of nursing clinical reasoning as defined by Levett-Jones et al. [24]. The questionnaire initially described by Koivisto et al. was modified by adding 2 specific questions on clinical deterioration described by Liou et al. [20, 39]. The modified questionnaire was translated into French by the research group (A.B. and D.B.). Each question assesses a specific step of the clinical reasoning process ("I learned

Table 1 Example of script concordance test

\begin{tabular}{|c|c|c|c|c|c|c|c|}
\hline \multirow{2}{*}{$\frac{\mathrm{N}^{\circ}}{1.1}$} & \multirow{2}{*}{$\begin{array}{l}\text { If you were thinking of... } \\
\text { Anticipating the drawing of a blood count }\end{array}$} & \multirow{2}{*}{$\begin{array}{l}\text { And then you find that ... } \\
\text { His heart rate is } 120 \text { beats/ min }\end{array}$} & \multicolumn{5}{|c|}{ this hypothesis becomes ... (circle your answer) } \\
\hline & & & -2 & -1 & 0 & 1 & \\
\hline 1.2 & drawing a capillary blood glucose & His blood pressure is $80 / 40 \mathrm{mmHg}$ & -2 & -1 & 0 & 1 & \\
\hline 1.3 & Calling the physician & He has abdominal pain & -2 & -1 & 0 & 1 & 2 \\
\hline
\end{tabular}

You are a nurse in the Surgery Department

A 45-year-old patient who has undergone splenectomy 2 days ago calls you because he feels some discomfort. He has a history of hypertension

-2 Much less likely

- 1 Less likely

0 Neither more nor less likely

+1 More likely

+2 Much more likely 
to ...." ) using a five-point Likert scale. A global score (graded out of 75) was obtained by adding values given to the 15 questions [20, 24, 39]. Moreover, the students' perceived satisfaction, their motivation toward learning the specific topic and the effectiveness of the instructional design were assessed by a questionnaire at the end of the session with a Likert scale (1 to 10) corresponding to level 1 and 3 of the Kirkpatrick training evaluation model [40].

\section{Statistical analysis}

The primary outcome was the students' clinical reasoning skills regarding the detection of clinical deterioration as measured by the SCTs. We assumed that the traditional teaching group would reach an average score of $65 / 100$ together with a standard deviation of 10/100 and, that the new training modality would improve the score by at least one standard deviation (mean difference 10/ 100 before-after). Accordingly, the sample size was set to 50 students per group using an alpha risk of $5 \%$ and beta risk of $10 \%$ with a two-sided two sample t-test ( $R$ software, https://marne.u707.jussieu.fr/biostatgv/). In view of the risk of attrition, each group was composed of 73 students.

The results are presented as mean \pm standard deviation or percentage and confidence intervals. After assessing normal distribution, statistical analysis was performed with the use of parametric tests (Student's $t$ test or $\mathrm{Chi}^{2}$ test) (JMP software, SAS institute ${ }^{\ominus}$ ). A $p$ value less than 0.05 was considered significant. For multiple comparisons, a Bonferroni correction was applied and the statistical significance threshold was lowered to 0.003 (alpha/15).

\section{Ethical statement}

This study was approved by The Institutional Review Board of SFAR (IRB-00010254-2017-044). The project had been registered on ClinicalTrials.gov (NCT03428269) [41]. The study was carried out with the use of the CONSORT tool adapted for simulation studies and the GREET Tool for educational studies [42].

\section{Results}

\section{Participants}

Five training sessions were organized in the 4 nursing institutes in February 2018. In total, 146 voluntary nursing students were included and randomized: $n=73$ in the SG group and $n=73$ in the TT group. No exclusion was observed (Fig. 2). Participant characteristics are presented in Table 2 and no significant differences were observed. The students of both groups did not differ in their experience regarding the clinical situations presented.

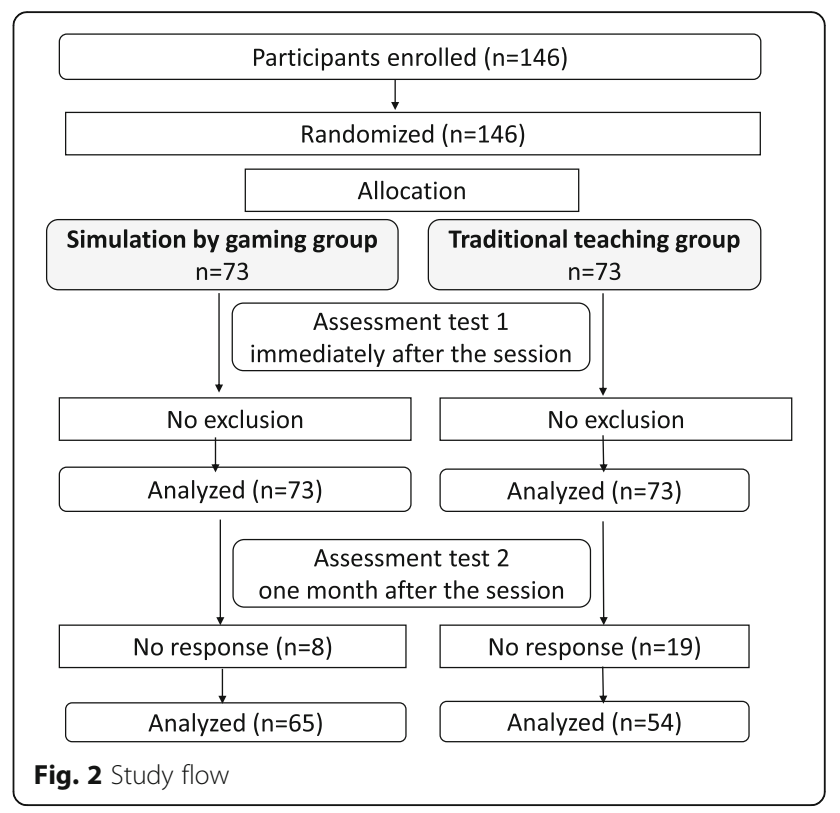

SCTs results immediately after the session (primary outcome) and 1 month later

Immediately after the session, the mean SCT scores were $58.9 \pm 9.1$ in the SG group and $57.8 \pm 8$ in the TT group with no significant difference $(p=0.43)$ (Fig. 3). One month later, 119 nurse students answered the SCTs $(n=$ 119/146): $n=65$ in the SG group and $n=54$ in the TT group. The mean SCT scores were $58.5 \pm 10.2$ in the SG group and $58 \pm 9.1$ in the TT group ( $p=0.77$ ) (Fig. 3). Scores obtained immediately after the session and 1 month later were not significantly different between groups.

\section{Self-assessment of clinical reasoning}

Following the training session, all students said that their knowledge of the different steps of the clinical reasoning process had increased. The scores were all above 3.4/5 with no significant difference between groups (Table 3 ).

\section{Satisfaction, motivation and professional transfer}

Students in the SG group significantly expressed significantly more satisfaction toward the training session than those in the TT group $(p=0.001)$ (Table 4).

Moreover, regarding the pedagogical tool used for training, the students of the SG group expressed more satisfaction than those in the TT group $(p=0.04)$. Students of the SG group perceived the training session as more engaging, as reflected by their significantly increased motivation $(p=0.003)$.

The global educational value (Would you recommend this training to students or colleagues?) was more positively significant in the SG group $(p=0.002)$. Both 
Table 2 Participant characteristics

\begin{tabular}{llll}
\hline & SG group $(n=73)$ & T group $(n=73)$ & 0.39 \\
\hline Age (years) (mean \pm SD) & $24 \pm 6.4$ & $25 \pm 6.5$ & $65 / 8(89 / 11 \%)$ \\
Sex (F/M) $n(\%)$ & $59 / 14(81 / 19 \%)$ & \\
Video gaming activity: $n(\%)$ & & $43(59 \%)$ & $12(16 \%)$ \\
Never & $39(53 \%)$ & $13(18 \%)$ \\
$1 /$ month & $11(15 \%)$ & $4(6 \%)$ \\
$1 /$ week & $10(14 \%)$ & $1(1 \%)$ \\
Everyday & $13(18 \%)$ & \\
No response & $0(0 \%)$ & $13(18 \%)$ \\
Video gaming activity in healthcare: \% of players & & $60(82 \%)$ \\
Yes & $13(18 \%)$ & $0(0 \%)$ \\
No & $59(81 \%)$ & \\
No response & $1(1 \%)$ & $2.3 \pm 1.8$ \\
Previous experience of clinical situations presented in the course: 1 (no) to 10 (expert) & $2.6 \pm 2.0$ \\
Brain trauma & $2.7 \pm 2.1$ & $3.0 \pm 2.4$ & 0.97 \\
Postoperative hemorrhage & & 0.39 \\
\hline
\end{tabular}

Results are presented as mean \pm standard deviation, or percentage. Comparisons were carried out with the use of the Student's $t$ test on means, or a Chi ${ }^{2}$ test on percentages

*: $p$ value less than 0.05 was considered significant

groups declared that the session could have an impact on their future professional work but the difference failed to reach significance (Table 4).

\section{Discussion}

In this study in which we assessed clinical reasoning skills to detect patient deterioration, we found no significant difference between a serious game-based simulation format and a traditional teaching method immediately and 1 month after training. However, the students expressed more satisfaction and motivation with the innovative teaching method.
The education of nurses, who are frontline healthcare providers, is essential to improve the detection of patient deterioration. Serious games dedicated to the same learning objective have already been created by others [19-22]. In Australia, a web-based esimulation program suggested an improvement of clinical knowledge of patient deterioration and enhanced students' self-assessed of knowledge, skills, confidence, and competence [19]. Similar results were obtained by Liaw et al. in nurses working on surgical wards [21, 22] and another team also used a serious game to explore the learning process of nursing

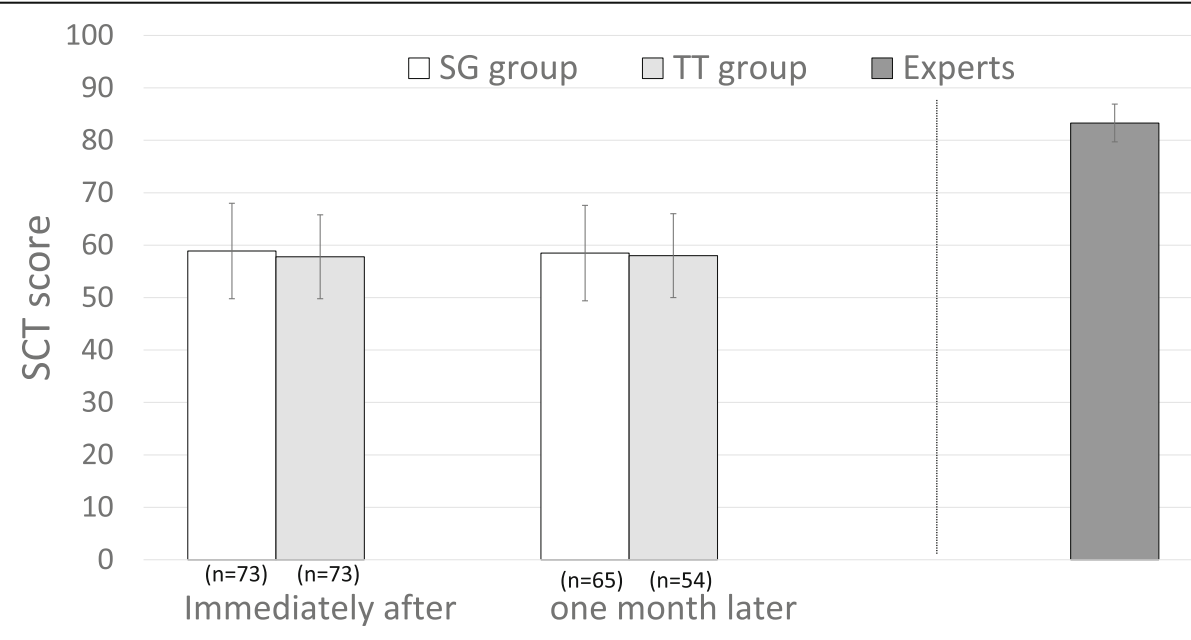

Fig. 3 SCT score immediately and 1 month after the session in SG group and TT group 
Table 3 Results of self-assessment of learning the clinical reasoning process between groups

\begin{tabular}{|c|c|c|c|}
\hline I learned: 1 (not at all) to 5 (very much) & SG group $(n=73)$ & $\Pi$ group $(n=73)$ & $p$ \\
\hline \multicolumn{4}{|l|}{ To collect information } \\
\hline Collect information by interviewing the patient & $4.0 \pm 1.0$ & $3.6 \pm 1.2$ & 0.02 \\
\hline Collect information by observing the patient & $4.2 \pm 0.8$ & $4.0 \pm 1.0$ & 0.19 \\
\hline Collect information from measurable patient data & $4.2 \pm 0.8$ & $4.2 \pm 0.9$ & 0.76 \\
\hline \multicolumn{4}{|l|}{ To process information } \\
\hline Analyze data to reach an understanding of signs or symptoms & $4.3 \pm 0.8$ & $4.3 \pm 0.8$ & 0.86 \\
\hline \multicolumn{4}{|l|}{ To identify problems/issues } \\
\hline Make nursing diagnosis & $4.2 \pm 0.8$ & $4.0 \pm 0.9$ & 0.10 \\
\hline Recognize possible early signs or symptoms when a patient's health deteriorates & $4.1 \pm 0.8$ & $4.1 \pm 0.9$ & 0.91 \\
\hline Make decisions on patient care independently & $4.1 \pm 0.8$ & $3.7 \pm 0.8$ & 0.004 \\
\hline Make decisions on patient care in cooperation with other students & $3.5 \pm 1.2$ & $3.0 \pm 1.1$ & 0.75 \\
\hline Make prompt decisions on patient care & $3.9 \pm 0.9$ & $3.8 \pm 0.9$ & 0.30 \\
\hline \multicolumn{4}{|l|}{ To establish goals } \\
\hline Prioritize patient's need for care & $3.7 \pm 1.0$ & $3.9 \pm 1.1$ & 0.24 \\
\hline Set goals & $3.4 \pm 1.0$ & $3.4 \pm 1.2$ & 0.82 \\
\hline Plan nursing interventions & $3.5 \pm 1.1$ & $3.6 \pm 1.1$ & 0.54 \\
\hline \multicolumn{4}{|l|}{ To take action } \\
\hline Implement nursing interventions & $4.1 \pm 0.9$ & $4.1 \pm 0.7$ & 0.61 \\
\hline Communicate vital information clearly based on the patient's current condition & $4.4 \pm 0.8$ & $4.3 \pm 0.9$ & 0.42 \\
\hline \multicolumn{4}{|l|}{ To evaluate outcome } \\
\hline Evaluate effectiveness of interventions & $3.9 \pm 0.9$ & $3.8 \pm 1.1$ & 0.44 \\
\hline Total scoring (/75) & $59.5 \pm 0.9$ & $57.8 \pm 1.0$ & 0.25 \\
\hline
\end{tabular}

Results are presented as mean \pm standard deviation and comparisons were carried out with the use of the Student's $t$ test. The Bonferroni criterion was set at alpha/ $15=0.003$ to reach statistical significance

students 'clinical reasoning, using a self-assessment questionnaire [20]. However, none of the abovementioned studies included a traditional educational modality as a control group. Moreover, an objective and quantitative assessment method such as SCT has rarely been used [43].

In education, the learning process can be explored using the learning levels described by Kirkpatrick [40]. Our study showed no difference between the two methods (simulation with serious game vs traditional teaching) with regard to the improvement of clinical reasoning skills necessary to detect patient deterioration (Kirkpatrick level 2). This result was obtained by comparing not only SCT scores, but also by some questions measuring the self-assessment of the different steps of the clinical reasoning process. Our results are consistent with those of Dankbarr et al. and show that serious games and e-modules are equally effective in developing

Table 4 Results of satisfaction, motivation and professional impact self-assessment

\begin{tabular}{|c|c|c|c|}
\hline & SG group $(n=73)$ & $\Pi$ group $(n=73)$ & $p$ \\
\hline $\begin{array}{l}\text { Are you globally satisfied with this training course? } \\
1 \text { (not satisfied) to } 10 \text { (very satisfied) }\end{array}$ & $8.5 \pm 1.6$ & $7.6 \pm 1.7$ & $0.001^{*}$ \\
\hline $\begin{array}{l}\text { Are you globally satisfied with the educational tool used for case-based learning? } \\
1 \text { (not satisfied) to } 10 \text { (very satisfied) }\end{array}$ & $8.5 \pm 1.4$ & $8.0 \pm 1.6$ & 0.04 \\
\hline $\begin{array}{l}\text { Do you think that this training course motivates you to learn? } \\
1 \text { (absolutely not) to } 10 \text { (agree absolutely) }\end{array}$ & $8.7 \pm 1.9$ & $7.7 \pm 2.0$ & $0.003^{*}$ \\
\hline $\begin{array}{l}\text { Do you think that this training will have an impact on your future professional work? } \\
1 \text { (absolutely not) to } 10 \text { (agree absolutely) }\end{array}$ & $8.3 \pm 1.8$ & $7.7 \pm 1.7$ & 0.06 \\
\hline $\begin{array}{l}\text { Would you recommend this training to students or colleagues? } \\
1 \text { (absolutely not) to } 10 \text { (agree absolutely) }\end{array}$ & $8.8 \pm 1.7$ & $7.8 \pm 2.0$ & $0.002^{*}$ \\
\hline
\end{tabular}

Results are presented as mean \pm standard deviation or percentage. Comparisons were carried out with the use of the Student's $t$ test or a Chi ${ }^{2}$ test. The Bonferroni criterion was set at alpha/ $/ 5=0.01$ to reach statistical significance; * $p$ value less than 0.01 was considered significant 
knowledge in patient safety [16]. Drummond et al. also found that training medical students in the management of cardiopulmonary resuscitation with a serious game was as effective as using an online course [17]. Likewise, in a randomized study, Liaw et al. failed to show any difference between virtual patient and mannequin-based simulation in a refresher training course on managing deterioration [23]. By contrast, the randomized study of Mohan et al. evidenced an improved decision-making capacity in trauma triage with the use of an educational video game as compared to app-based training [15]. Other studies have compared the efficacy of different educational methods but in other healthcare domains (such as trauma, urology, surgery, pharmacy) and have also provided conflicting results for learning $[15,18,44$, 45]. In a recent systematic review, serious games used in health professions seem at least effective as a learning control method and may be more effective in improving knowledge and skills [13]. One major limitation of this review was the high level of heterogeneity. The existing studies were difficult to compare and generalizability difficult to reach due to the differences in the populations studied, the variety of the serious game assessment methods, the game designs, and the pedagogical objectives [10-14]. The definition itself of a serious game is sometimes ambiguous between e-learning, virtual patient and serious game [46]. In our study, serious games are defined as video games developed specifically with an educational purpose [7]. Finally, in the 30 randomized clinical trials included in this systematic review, no study assessing the detection of clinical deterioration was included [13]. This is therefore important to better specify the place of the serious games in professional healthcare education and their educative impact, especially on professional practice.

In the studies described above, the clinical reasoning skills were poorly assessed. In most studies, the knowledge or the end-result of the clinical reasoning process (diagnostic or treatment), but not the clinical reasoning process itself, were assessed. In our study, we tried to explore the clinical reasoning skills and all different steps of the clinical reasoning process using firstly a method, i.e. SCT, which has been validated as an effective tool of assessing clinical reasoning skills [33-36, 43]. The SCTs used in our study were related to the content and the educational objectives (clinical deterioration) of the serious games used by students. This was a concern in order to link the strategy to a theoretical learning model of clinical reasoning, the script theory. The final decisions tested with our SCTs explored many different nurse decisions (diagnosis but also treatment or action to perform). SCT is an objective and quantitative assessment method which reduces interpretation bias. Secondly, self-assessment of the different steps of clinical reasoning was obtained with the use of a modified tool $[20,39]$. This tool explores the process by which nurses collect information, process the information, identify problems/issues, establish goals, take action, and evaluate outcomes. Recently, and after the beginning of our study, Liaw et al. published a study describing another specific tool used to assess clinical reasoning in clinical deterioration which, on the whole, used the same criteria as our own study [47]. The weaknesses in the previous literature as well as the neutral results (including ours) could be explained by the difficulty to assess clinical reasoning, the complexity of education, and the need to explore results in the long-term.

Learning retention is essential but has been less studied. Similar to our results, Drummond et al. found no difference in the management of cardiopulmonary resuscitation (by means of a mastery learning checklist) 4 months after training of medical students with a SG or an online course [17]. By contrast, the previously mentioned study of Mohan et al. showed an improved decision-making capacity in trauma triage 6 months after initial training with the use of an educational video game compared to traditional apps [15].

As described by Kirkpatrick, satisfaction is the first step of the learning process [40]. In the present study, the students were globally satisfied with the training received and the educational tool used. However, satisfaction was greater in the SG group. Satisfaction associated with the use of a serious game is often described but not always by using a blind comparison design $[48,49]$. Boeker et al. reported significantly higher satisfaction in an urology adventure game group compared to a group using a written script [45]. Serious gaming may improve satisfaction compared to traditional learning and other modalities of digital education [13]. Moreover, our students perceived this training session as more engaging and providing significantly higher motivation in the SG group. These results collectively confirm that learners are very motivated to use serious games as they are more engaging, interactive and provide more continuous feedback than traditional learning methods $[16,45,50,51]$ or e-modules [16]. Although motivation and satisfaction are complex psychological processes, the motivational effect is important in education and might be associated with better learning outcomes $[8,52,53]$. Increased satisfaction and motivation when a new pedagogical tool is used could engage the student to learn more, and this could have long-term impact. Active learning is known to increase students' performance in various scientific domains [54] and this could also be true for simulation by gaming in the medical field.

Professional attitudes have been less studied, and there is limited evidence of a beneficial effect of using a serious game [13]. In the present study, both the SG and 
the TT group similarly declared that the session could have an impact on their future professional work but no significant difference was found between the two groups (level 3 of the Kirkpatrick training evaluation model).

The present study was original as it included instructor-standardized debriefing after the serious game session in a way similar to debriefing carried out in high fidelity simulation [25]. Our objective was to evaluate a simulation method using serious games and not just the game itself. The importance of instructor-led debriefing is well demonstrated in simulation in medical education $[31,32]$. However, paradoxically, its place is extremely limited in the use of serious games. This could be explained by the frequent online use of these games, which is more compatible with digital feedback $[16,19,26]$. In many studies, games are played in the presence of instructors who are able to interact with the players but surprisingly no standardized debriefing is performed [20, 43]. It is therefore unknown if the addition of debriefing to the SG session is of any educational value or not. In our study, digital feedback was included in the serious game, but an instructor-standardized debriefing with the players (reaction, analysis and synthesis phases) was added. Importantly, this did not improve the learning efficacy as results were similar to those obtained after the traditional training method. Additional studies are necessary to seek the efficacy of serious game including or not a debriefing session on clinical reasoning skills .

\section{Limitations}

One limitation in studies such as ours is the difficulty in assessing clinical reasoning skills as it is a complex process. We used SCTs as, in education literature, they are reported to be a well-validated evaluation method [33-36]. Our SCTs were carefully prepared and followed the guidelines described by Charlin et al. and Fournier et al. to obtain adequate fidelity and validity [33-36]. Although our students were trained to use SCTs before the beginning of the session, the training lasted $5 \mathrm{~min}$ only and it may be that some students had not fully understood how to correctly answer the questions. Nevertheless, the mean student SCT score (57.8 to 58.9) and the mean expert SCT score (83.3) in our study are similar to those previously described in the literature, which suggests that our use of SCTs was correct [43]. In addition, self-assessment was equally used to assess the various steps of the nursing clinical reasoning process but this part is less validated, as it rests on student's perception only [20, 24, 39, 47].

An additional limitation may be related to the use of only 2 cases which might have reduced the impact of the training course. However, the SCTs did explore the same theme of clinical deterioration detection in both groups. Thus, the lack of difference between the two groups could be explained by the short duration of training (total: $2 \mathrm{~h}$ ). In addition, no pretest knowledge was assessed as we expected a learning bias related to the use of the same SCTs. Moreover, the session could not be prolonged for practical reasons, and adding 80 SCTs would have reduced the time dedicated to the training itself. The pretest was not essential to compare the groups before, as both groups of students had the same low level of clinical experience and had the same basic knowledge (2nd year and same curriculum).

\section{Conclusion}

In this study, clinical reasoning was assessed in nursing students immediately and 1 month after a training course dedicated to the detection of patient deterioration. No significant educational difference between training with a serious game-based simulation course and a traditional teaching course was found. However, satisfaction and motivation were greater when the training involved a serious game-based simulation. Simulation by gaming could positively impact the long-term results of nurses' education on clinical reasoning.

\section{Additional files}

Additional file 1 Screenshot of LabForGames Warning serious game.

Additional file 2. Text paper format of the 2 cases (traditional teaching group).

Additional file 3. PowerPoint slide kit of traditional teaching course (traditional teaching group).

\section{Abbreviations}

CR: Clinical reasoning; SBAR: Situation, background, assessment, recommendation; SCT: Script concordance tests; SG: Simulation by gaming; TT: Traditional teaching

\section{Acknowledgements}

We would like to acknowledge the LabForGames Warning project team members (Philippe Roulleau, Bonga Barcello De Carvalho, Hélène Bertrand, Alain Cazin, Véronique Mahon, Lionel Henriques, Nathalie Léon, Vincent Lebreton, Laure Legoff, Aurélie Woda, Bertrand Bech, Alexandre Renault) and the instructors of the four nursing institutes (Sud Francilien, Perray Vaucluse, Paul Guiraud and Etampes).

\section{Authors' contributions \\ $A B$ designed the study, performed the inclusion, analyzed and interpreted the data regarding the serious game and was a major contributor in writing the manuscript. MAA analyzed and interpreted the data regarding the serious game and was a contributor in writing the manuscript. DB designed the study, analyzed and interpreted the data regarding the serious game and was a contributor in writing the manuscript. All authors read and approved the final manuscript.}

\section{Funding}

Agence Régionale de Santé lle de France (French regional authority for health regulation) which selected the serious game project and provided a grant to create the serious game project and mainly pay for the

development of the game in 2014 (before this research). Agence Régionale de Santé lle de France did not provide a grant for the research project. None of the authors received any personal financial support. 


\section{Availability of data and materials}

The datasets used and/or analyzed during the current study are available from the corresponding author on reasonable request.

\section{Ethics approval and consent to participate}

This study was approved by The Institutional Review Board of SFAR (French Society of Anesthesia and Intensive Care Medicine) (IRB-00010254-2017-044). All participants were informed and consented.

\section{Consent for publication}

Not applicable.

\section{Competing interests}

The authors declare that they have no competing interests.

\section{Author details}

${ }^{1}$ Centre de simulation LabForSIMS, Faculté de médecine Paris Saclay, 94275 Le Kremlin Bicêtre, France. ${ }^{2}$ Département d'Anesthésie-Réanimation, CHU Bicêtre, 78, rue du Général Leclerc, 94275 Le Kremlin Bicêtre, France. ${ }^{3}$ CIAMS, Univ. Paris-Sud, Université Paris-Saclay, 91405 Orsay Cedex, France. ${ }^{4} \mathrm{CIAMS}$, Université d'Orléans, 45067 Orléans, France.

Received: 11 October 2019 Accepted: 16 January 2020

Published online: 19 February 2020

\section{References}

1. Buist M, Bernard S, Nguyen TV, Moore G, Anderson J. Association between clinically abnormal observations and subsequent in-hospital mortality: a prospective study. Resuscitation. 2004;62(2):137-41.

2. Hillman KM, Bristow PJ, Chey T, Daffurn K, Jacques T, Norman SL, Bishop GF, Simmons $G$. Duration of life-threatening antecedents prior to intensive care admission. Intensive Care Med. 2002;28(11):1629-34.

3. Ghaferi AA, Birkmeyer JD, Dimick JB. Complications, failure to rescue, and mortality with major inpatient surgery in medicare patients. Ann Surg. 2009; 250(6):1029-34.

4. Cook DA, Hatala R, Brydges R, Zendejas B, Szostek JH, Wang AT, Erwin PJ, Hamstra SJ. Technology-enhanced simulation for health professions education: a systematic review and meta-analysis. JAMA. 2011;306(9):978-88.

5. McGaghie WC, Issenberg SB, Cohen ER, Barsuk JH, Wayne DB. Does simulation-based medical education with deliberate practice yield better results than traditional clinical education? A meta-analytic comparative review of the evidence. Acad Med. 2011;86(6):706-11.

6. Cook DA, Brydges R, Zendejas B, Hamstra SJ, Hatala R. Technologyenhanced simulation to assess health professionals: a systematic review of validity evidence, research methods, and reporting quality. Acad Med. 2013; 88(6):872-83.

7. Bergeron BP. Developing serious games: Charles River media; 2006

8. Hamari J, Shernoff DJ, Rowe E, Coller B, Asbell-Clarke J, Edwards T. Challenging games help students learn: an empirical study on engagement, flow and immersion in game-based learning. Comput Hum Behav. 2016;54: 170-9.

9. Kolb AY, Kolb DA. Learning styles and learning spaces: enhancing experiential learning in higher education. Acad Manag Learn Educ. 2005;4: 193-212.

10. Graafland M, Schraagen JM, Schijven MP. Systematic review of serious games for medical education and surgical skills training. Br J Surg. 2012; 99(10):1322-30.

11. Cook DA, Erwin PJ, Triola MM. Computerized virtual patients in health professions education: a systematic review and meta-analysis. Acad Med. 2010;85(10):1589-602.

12. Wang R, DeMaria S Jr, Goldberg A, Katz D. A systematic review of serious games in training health care professionals. Simul Healthc. 2016;11(1):41-51.

13. Gentry SV, Gauthier A, L'Estrade Ehrstrom B, Wortley D, Lilienthal A, Tudor Car L, Dauwels-Okutsu S, Nikolaou CK, Zary N, Campbell J, et al. Serious gaming and Gamification education in health professions: systematic review. J Med Internet Res. 2019;21(3):e12994.

14. Gorbanev I, Agudelo-Londono S, Gonzalez RA, Cortes A, Pomares A, Delgadillo V, Yepes FJ, Munoz O. A systematic review of serious games in medical education: quality of evidence and pedagogical strategy. Med Educ Online. 2018;23(1):1438718.
15. Mohan D, Farris C, Fischhoff B, Rosengart MR, Angus DC, Yealy DM, Wallace DJ, Barnato AE. Efficacy of educational video game versus traditional educational apps at improving physician decision making in trauma triage: randomized controlled trial. BMJ. 2017;359:j5416.

16. Dankbaar ME, Richters O, Kalkman CJ, Prins G, Ten Cate OT, van Merrienboer JJ, Schuit SC. Comparative effectiveness of a serious game and an e-module to support patient safety knowledge and awareness. BMC Med Educ. 2017;17(1):30.

17. Drummond D, Delval P, Abdenouri S, Truchot J, Ceccaldi PF, Plaisance P, Hadchouel A, Tesniere A. Serious game versus online course for pretraining medical students before a simulation-based mastery learning course on cardiopulmonary resuscitation: a randomised controlled study. Eur J Anaesthesiol. 2017;34(12):836-44.

18. Berger J, Bawab N, De Mooij J, Sutter Widmer D, Szilas N, De Vriese C, Bugnon $\mathrm{O}$. An open randomized controlled study comparing an online text-based scenario and a serious game by Belgian and Swiss pharmacy students. Curr Pharm Teach Learn. 2018;10(3):267-76.

19. Bogossian FE, Cooper SJ, Cant R, Porter J, Forbes H, Team FAR. A trial of esimulation of sudden patient deterioration (FIRST2ACT WEB) on student learning. Nurse Educ Today. 2015;35(10):e36-42.

20. Koivisto JM, Multisilta J, Niemi H, Katajisto J, Eriksson E. Learning by playing: a cross-sectional descriptive study of nursing students' experiences of learning clinical reasoning. Nurse Educ Today. 2016;45:22-8.

21. Liaw SY, Wong LF, Lim EY, Ang SB, Mujumdar S, Ho JT, Mordiffi SZ, Ang EN. Effectiveness of a web-based simulation in improving Nurses' workplace practice with deteriorating Ward patients: a pre- and Postintervention study. J Med Internet Res. 2016;18(2):e37.

22. Liaw SY, Chng DYJ, Wong LF, Ho JTY, Mordiffi SZ, Cooper S, Chua WL, Ang ENK. The impact of a web-based educational program on the recognition and management of deteriorating patients. J Clin Nurs. 2017;26(23-24):4848-56.

23. Liaw SY, Chan SW, Chen FG, Hooi SC, Siau C. Comparison of virtual patient simulation with mannequin-based simulation for improving clinical performances in assessing and managing clinical deterioration: randomized controlled trial. J Med Internet Res. 2014;16(9):e214.

24. Levett-Jones T, Hoffman K, Dempsey J, Jeong SY, Noble D, Norton CA, Roche J, Hickey N. The 'five rights' of clinical reasoning: an educational model to enhance nursing students' ability to identify and manage clinically 'at risk' patients. Nurse Educ Today. 2010;30(6):515-20.

25. Fanning RM, Gaba DM. The role of debriefing in simulation-based learning. Simul Healthc. 2007;2(2):115-25.

26. Middeke A, Anders S, Schuelper M, Raupach T, Schuelper N. Training of clinical reasoning with a serious game versus small-group problem-based learning: a prospective study. PLoS One. 2018;13(9):e0203851.

27. Site legifrance.gouv. https://www.legifrance.gouv.fr/affichTexte.do?cidTexte= JORFTEXT000020961044

28. Gao H, McDonnell A, Harrison DA, Moore T, Adam S, Daly K, Esmonde L, Goldhill DR, Parry GJ, Rashidian A, et al. Systematic review and evaluation of physiological track and trigger warning systems for identifying at-risk patients on the ward. Intensive Care Med. 2007;33(4):667-79.

29. Nagpal K, Arora S, Vats A, Wong HW, Sevdalis N, Vincent C, Moorthy K. Failures in communication and information transfer across the surgical care pathway: interview study. BMJ Qual Saf. 2012;21(10):843-9.

30. Mackintosh N, Sandall J. Overcoming gendered and professional hierarchies in order to facilitate escalation of care in emergency situations: the role of standardised communication protocols. Soc Sci Med. 2010;71(9):1683-6.

31. Guide bonnes pratiques simulation sante. https://www.has-sante.fr/upload/ docs/application/pdf/2013-01/guide_bonnes_pratiques_simulation_sante_ guide.pdf. Accessed 28 Jan 2020.

32. Salas E, Klein C, King H, Salisbury M, Augenstein JS, Birnbach DJ, Robinson DW, Upshaw C. Debriefing medical teams: 12 evidence-based best practices and tips. Jt Comm J Qual Patient Saf. 2008;34(9):518-27.

33. Dory V, Gagnon R, Vanpee D, Charlin B. How to construct and implement script concordance tests: insights from a systematic review. Med Educ. 2012; 46(6):552-63.

34. Fournier JP, Demeester A, Charlin B. Script concordance tests: guidelines for construction. BMC Med Inform Decis Mak. 2008:8:18.

35. Lubarsky S, Charlin B, Cook DA, Chalk C, van der Vleuten CP. Script concordance testing: a review of published validity evidence. Med Educ. 2011:45(4):329-38.

36. Deschenes MF, Charlin B, Gagnon R, Goudreau J. Use of a script concordance test to assess development of clinical reasoning in nursing students. J Nurs Educ. 2011;50(7):381-7. 
37. Deschênes MF, Goudreau J. Addressing the development of both knowledge and clinical reasoning in nursing through the perspective of script concordance: an integrative literature review. J Nurs Educ. 2017;7(12): 28-38.

38. Charlin B, Gagnon R, Lubarsky S, Lambert C, Meterissian S, Chalk C, Goudreau J, van der Vleuten C. Assessment in the context of uncertainty using the script concordance test: more meaning for scores. Teach Learn Med. 2010;22(3):180-6.

39. Liou SR, Liu HC, Tsai HM, Tsai YH, Lin YC, Chang CH, Cheng CY. The development and psychometric testing of a theory-based instrument to evaluate nurses' perception of clinical reasoning competence. J Adv Nurs. 2016;72(3):707-17.

40. Rouse DN. Employing Kirkpatrick's evaluation framework to determine the effectiveness of health information management courses and programs. Perspect Health Inf Manag. 2011;8:1c.

41. Cheng A, Kessler D, Mackinnon R, Chang TP, Nadkarni VM, Hunt EA, DuvalArnould J, Lin Y, Cook DA, Pusic M, et al. Reporting guidelines for health care simulation research: extensions to the CONSORT and STROBE statements. Adv Simul (Lond). 2016;1:25.

42. Phillips AC, Lewis LK, McEvoy MP, Galipeau J, Glasziou P, Moher D, Tilson JK, Williams MT. Development and validation of the guideline for reporting evidence-based practice educational interventions and teaching (GREET). BMC Med Educ. 2016;16(1):237.

43. Schubach F, Goos M, Fabry G, Vach W, Boeker M. Virtual patients in the acquisition of clinical reasoning skills: does presentation mode matter? A quasi-randomized controlled trial. BMC Med Educ. 2017;17(1):165.

44. Graafland M, Bemelman WA, Schijven MP. Game-based training improves the surgeon's situational awareness in the operation room: a randomized controlled trial. Surg Endosc. 2017;31(10):4093-101.

45. Boeker $M$, Andel $P$, Vach W, Frankenschmidt A. Game-based e-learning is more effective than a conventional instructional method: a randomized controlled trial with third-year medical students. PLoS One. 2013;8(12): e82328.

46. Cant R, Cooper S, Sussex R, Bogossian F. What's in a name? Clarifying the nomenclature of virtual simulation. Clin Simul Nurs. 2019;27:26-30.

47. Liaw SY, Rashasegaran A, Wong LF, Deneen CC, Cooper S, Levett-Jones T, Goh HS, Ignacio J. Development and psychometric testing of a clinical reasoning evaluation simulation tool (CREST) for assessing nursing students' abilities to recognize and respond to clinical deterioration. Nurse Educ Today. 2018;62:74-9.

48. Johnsen HM, Fossum M, Vivekananda-Schmidt P, Fruhling A, Slettebo A. A serious game for teaching nursing students clinical reasoning and decisionmaking skills. Stud Health Technol Inform. 2016;225:905-6.

49. Pasquier P, Merat S, Malgras B, Petit L, Queran X, Bay C, Boutonnet M, Jault $P$, Ausset $S$, Auroy $Y$, et al. A serious game for massive training and assessment of French soldiers involved in forward combat casualty care (3D-SC1): development and deployment. JMIR Serious Games. 2016;4(1):e5.

50. Dankbaar ME, Alsma J, Jansen EE, van Merrienboer JJ, van Saase JL, Schuit SC. An experimental study on the effects of a simulation game on students' clinical cognitive skills and motivation. Adv Health Sci Educ Theory Pract. 2016;21(3):505-21.

51. Kaczmarczyk J, Davidson R, Bryden D, Haselden S, Vivekananda-Schmidt P. Learning decision making through serious games. Clin Teach. 2016;13(4): $277-82$.

52. Cook DA, Hamstra SJ, Brydges R, Zendejas B, Szostek JH, Wang AT, Erwin PJ, Hatala R. Comparative effectiveness of instructional design features in simulation-based education: systematic review and meta-analysis. Med Teach. 2013;35(1):e867-98.

53. Drummond D, Hadchouel A, Tesniere A. Serious games for health: three steps forwards. Adv Simul (Lond). 2017;2:3.

54. Freeman S, Eddy SL, McDonough M, Smith MK, Okoroafor N, Jordt H, Wenderoth MP. Active learning increases student performance in science, engineering, and mathematics. Proc Natl Acad Sci. 2014;111:8410-5.

\section{Publisher's Note}

Springer Nature remains neutral with regard to jurisdictional claims in published maps and institutional affiliations.

\section{Ready to submit your research? Choose BMC and benefit from}

- fast, convenient online submission

- thorough peer review by experienced researchers in your field

- rapid publication on acceptance

- support for research data, including large and complex data types

- gold Open Access which fosters wider collaboration and increased citations

- maximum visibility for your research: over $100 \mathrm{M}$ website views per year

At BMC, research is always in progress.

Learn more biomedcentral.com/submissions 